\title{
Study of the impact of treatment modes on hardness, deformability and microstructure of VT6 (Ti-6Al-4V) and VV751P (Ni-15Co-10Cr) alloy samples after selective laser sintering
}

\author{
Natalia V. Galkina, ${ }^{1, *}$, Ekaterina A. Nosova ${ }^{1}$, and Andrey V. Balaykin ${ }^{1}$ \\ ${ }^{1}$ Samara National Research University, Russia, 34, Moskovskoye Shosse, 443086, Samara, Russia
}

\begin{abstract}
Selective laser sintering is an advanced method for obtaining sophisticated products and assembly permanent joints. This is particularly relevant for heat resistant alloys employed in aviation equipment. Heat treatment modes traditionally applied to the products are chosen in accordance with conditions of further product operation. In this paper there are given the results of experimental study of hardness, deformability and microstructure of samples after selective laser sintering of $\mathrm{Ni}-15 \mathrm{Co}-10 \mathrm{Cr}$ and $\mathrm{Ti}-6 \mathrm{Al}-4 \mathrm{~V}$ alloy powders. It has been determined that $\mathrm{Ni}-15 \mathrm{Co}-10 \mathrm{Cr}$ alloy ageing increases the hardness and deformability of samples; these characteristics decrease if the ageing lasts for 9-19 hours. Annealing of Ti-6Al-4V alloy samples results in preserving original hardness. After complete annealing, the hardness of samples decreases from 32 ... 33HRC to 24 ... 26HRC. Microstructural studies showed that there are cracks between layers in the surface of Ti-6Al-4V alloy samples after sintering and not complete annealing. After full annealing, cracks' width and length decreased. Cracks in Ni-15Co-10Cr alloy samples' microstructure were not detected.
\end{abstract}

\section{Introduction}

Additive technologies have become popular in recent times. This is explained by the fact that final products can be derived by adding a layer of material [1]. Selective laser sintering is a metallic additive production in which parts are formed by melting of consecutive layers of powder particles using a laser beam [2 - 4]. Due to the fact that SLS enables to create functional parts of sophisticated forms, it is increasingly being used to manufacture parts in various areas of mechanical engineering, including aviation industry [5-7]. Heat resistant materials based on nickel and titanium alloys are well used in engine construction [8 - 11].

Due to the difference in the properties between sintered samples and those obtained by traditional methods, it is necessary to determine the reasons for these differences.

The purpose of this work was to indentify strength and plastic properties of sintered workpieces in comparison with traditionally used $\mathrm{Ti}-6 \mathrm{Al}-4 \mathrm{~V}$ and $\mathrm{Ni}-$ $15 \mathrm{Co}-10 \mathrm{Cr}$ alloy products, and to explain the result through a structure study with optical metallography methods.

\section{Materials and Method}

$2 \times 10 \times 30 \mathrm{~mm}$ samples were grown out of $\mathrm{Ni}-15 \mathrm{Co}-10 \mathrm{Cr}$ and $\mathrm{Ti}-6 \mathrm{Al}-4 \mathrm{~V}$ material with the method of selective sintering.
After growing, samples from $\mathrm{Ni}-15 \mathrm{Co}-10 \mathrm{Cr}$ material were quenched at a temperature of $1000^{\circ} \mathrm{C}$ for 1.5 hours, then at a temperature of $1180^{\circ} \mathrm{C}$ for $2.5-3$ hours, then in the furnace for $50-60 \mathrm{~min}$ at a temperature of $1050^{\circ} \mathrm{C}$; cooling together with the furnace to $1000^{\circ} \mathrm{C}$ takes place for 50-60 minutes; further cooling is in the air. After quenching, samples were aged at a temperature of $850^{\circ} \mathrm{C}$ for $3,6,9,12$ and 15 hours. Titanium alloy samples were annealed after sintering for one hour at a temperature of $750^{\circ} \mathrm{C}$ and $850^{\circ} \mathrm{C}$.

After heat treatment was carried out, the samples were subject to bending test in a tool-stamp with an apex angle of $90^{\circ}$ and a rounding radius of $10 \mathrm{~mm}$ [12].

In order to obtain a deformation index, the dimensions of bent samples were measured, particularly the height of curvilinear isosceles triangle's outer and inner sides and the length of the neutral layer. Deformability was evaluated according to the following formula:

$$
d=\frac{H_{\text {aver }}}{l_{H}}
$$

where $H_{\text {aver }}$ - is an average height of the curvilinear isosceles triangle; $l_{H}$ - is a neutral layer length.

Investigation of the structure of deformability index shows that the greater is the value of this index, the higher is deformability.

\footnotetext{
* Corresponding author: galkina nv@,ssau.ru
} 
From the samples obtained, microsections were produced. The etching of titanium alloy samples was carried out by concentrated hydrofluoric acid HF for 5 seconds. Etching was made as follows: $180 \mathrm{ml}$ of $\mathrm{H} 2 \mathrm{O}$, $180 \mathrm{ml}$ of HCL, $120 \mathrm{ml}$ of HNO3, $30 \mathrm{ml}$ of HF. Etching duration is 1-2 minutes, washing carried out with flowing water, drying performed with filter paper. After etching, microstructure was studied with metallographic instrumental microscope METAM LV-32.

For each sample, the hardness of the side surface was measured according to Rockwell with a diamond point.

\section{Results and Discussion}

Dependence of hardness change on the duration of ageing is shown in Fig. 1 and Fig. 2.

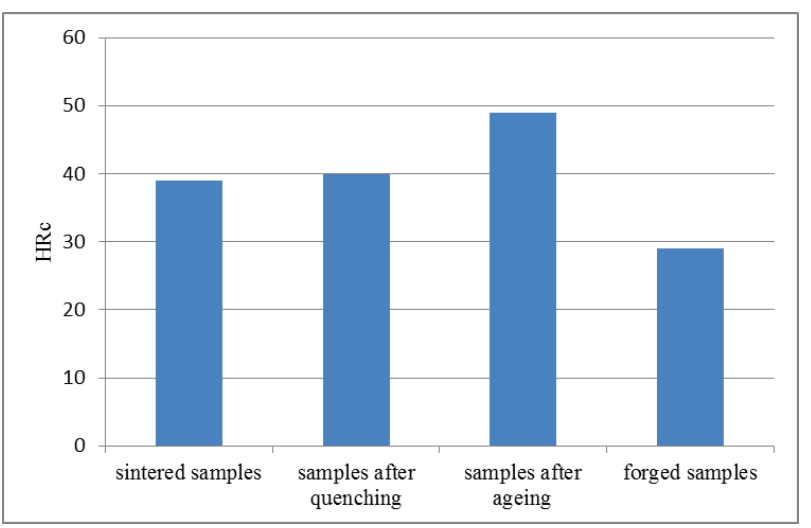

Fig. 1. Dependence of hardness change on the duration of ageing of Ni-15Co-10Cr alloy sample

Figure 1 shows that quenching and further ageing result in high levels of hardness. Compared to the values specified in Ni-15Co-10Cr compact alloy reference, the hardness should be 241-277HB, which corresponds to $24 \ldots$ 29HRC. These figures are significantly lower than those obtained after sintering, quenching and ageing.

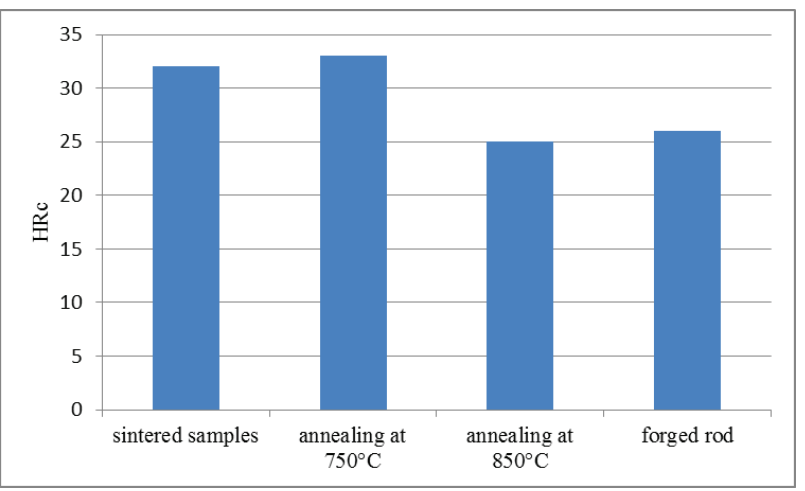

Fig. 2. Dependence of hardness change on annealing temperature for $\mathrm{Ti}-6 \mathrm{Al}-4 \mathrm{~V}$ alloy sample

As you can see from Fig. 2, the hardness of Ti-6Al$4 \mathrm{~V}$ alloy after not complete annealing at $750^{\circ} \mathrm{C}$ temperature for an hour remains rather high, but after full annealing at the temperature of $850^{\circ} \mathrm{C}$, the hardness decreases from $32 \ldots 33 \mathrm{HRC}$ to $24 \ldots 26 \mathrm{HRC}$, which is about $30 \%$. Ti-6Al-4V alloy rod after annealing, according to the standard, should have a hardness of 26..41 HRC. These figures show that the sintered samples are in the middle of specified limits, while the annealed samples' hardness corresponds to the lower boundary of the values specified in the standards.

Based on the measurements of the heights of curvilinear isosceles triangle, the deformability factor for each sample was calculated. As a result, there was determined the dependence of deformability factor on the time of ageing for $\mathrm{Ni}-15 \mathrm{Co}-10 \mathrm{Cr}$ material (Fig. 3) and the temperature of annealing for titanium alloy $\mathrm{Ti}-$ 6Al-4V (Fig. 4).

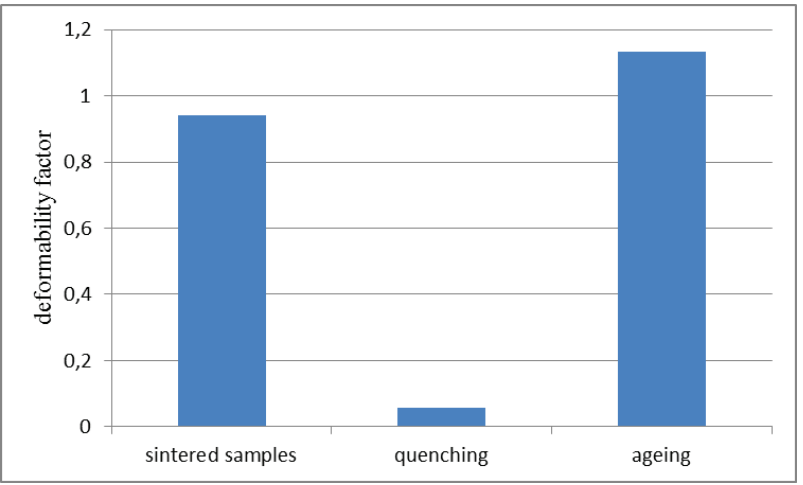

Fig. 3. Dependence of deformability factor on $\mathrm{Ni}-15 \mathrm{Co}-10 \mathrm{Cr}$ alloy treatment mode

The diagram in Fig. 3 shows that hardening and ageing increase deformability characteristics. For these geometric dimensions of curved samples, the relative elongation of the outer layer should be within $7.4 \ldots 8 \%$. These values are lower than the elongation for $\mathrm{Ni}-15 \mathrm{Co}-$ $10 \mathrm{Cr}$ alloy specified in standard, which amount to at least $12 \%$.

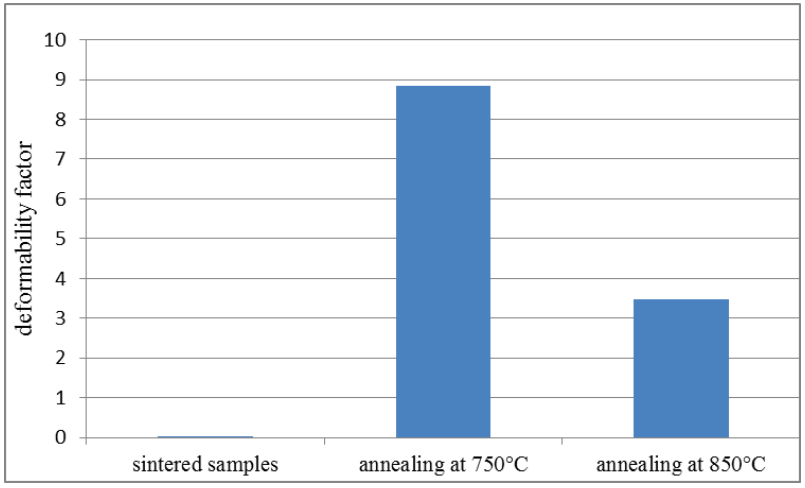

Fig. 4. Dependence of deformability factor on the temperature of annealing for $\mathrm{Ti}-6 \mathrm{Al}-4 \mathrm{~V}$ alloy

The chart in Figure 4 shows that Ti-6Al-4V alloy deformability after annealing increases compared to the original sintered state. For such deformability characteristics, the degree of deformation of the outer layer of bent samples shall be $0.4 \ldots 1.25 \%$. These values are an order of magnitude lower than the relative elongation specified in GOST for hot rolled rods from Ti-6Al-4V alloy, which shall be $8 . . .12$ percent. 


\section{Microstructure}

Microstructure of sintered samples is present on fig. 5-8.

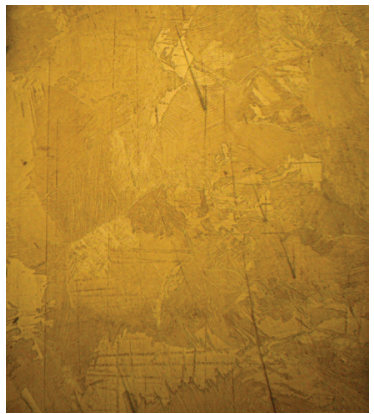

Fig. 5. Microstructure of Ni-15Co-10Cr after sintering, 100

From Fig. 5, structure of Ni-15Co-10Cr alloy samples after sintering is uniform, free of cracks.

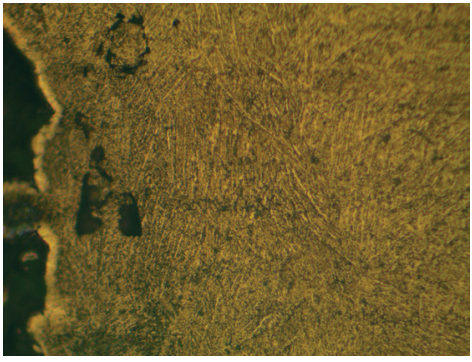

Fig. 6. Microstructure of sintered sample of Ti-6Al-4V alloy

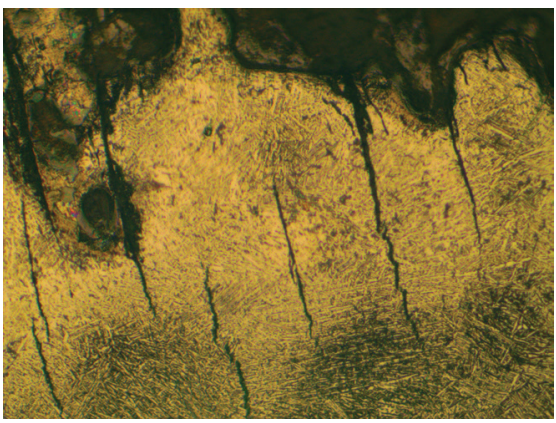

Fig. 7. Microstructure of sintered and annealed at $750^{\circ} \mathrm{C}$ sample of Ti-6Al-4V alloy

From Fig. 6-8, structure of Ti-6Al-4V alloy samples after sintering has cracks and unbaked particles. After incomplete annealing cracks stay in microstructure but after complete annealing they become less and shorter.

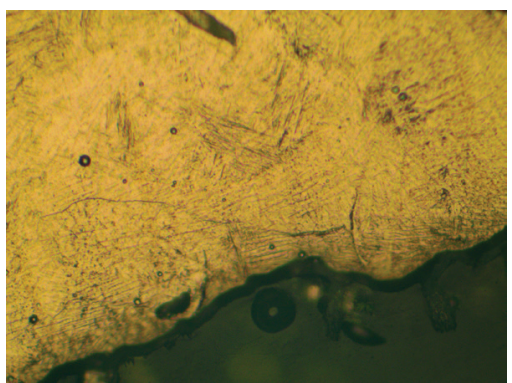

Fig. 8. Microstructure of sintered and annealed at $850^{\circ} \mathrm{C}$ sample of Ti-6Al-4V alloy

\section{Conclusions}

1. Sintered samplers obtained from powder of Ni-15Co$10 \mathrm{Cr}$ heat resistant alloy showed the decreased values of hardness, which is rises after quenching and aging. Comparison to forged rod, obtained samples had increased hardness due to over saluted structure of fast crystallized particles.

2. Samples sintered from $\mathrm{Ti}-6 \mathrm{Al}-4 \mathrm{~V}$ alloy showed increased values of hardness in comparison to deformed standard rods. Annealing at $850^{\circ} \mathrm{C}$ lead to decreasing of hardness, approaching to forged state.

3. Deformability of sintered Ni-15Co-10Cr alloy samples goes down after annealing but grows up after aging.

4. Deformability of samples sintered form Ti-6Al-4V alloy has maximum values after incomplete annealing.

5. Decreased deformability after sintering in samples Ti-6Al-4V alloy due to interlayer cracks, which are absent in samples sintered from $\mathrm{Ni}-15 \mathrm{Co}-10 \mathrm{Cr}$ alloy

\section{References}

1. I. Gibson, D.W. Rosen, B. Stucker, Additive Manufacturing Technologies (Springer, 2010)

2. Z. Hu, H. Zhu, H. Zhang, X. Zeng, opt. Laser Technol, 87, 17 (2017)

3. G. Casalino, S.L. Campanelli, N. Contuzzi, A.D. Ludovico, opt. Laser Technol, 65, 151 (2015)

4. Q. Shi, D. Gu, M. Xia, S. Cao, T. Rong, Opt. Laser Technol., 84, 9 (2016)

5. V.G Smelov., A.V Sotov, A.V. Agapovichev, IOP Conf. Series: Mat. Sc. Engin. 140, 1 (2016)

6. A.V. Agapovichev, V.V. Kokareva, V.G. Smelov, A.V. Sotov, IOP Conf. Series: Mat. Sc. Engin. 156, 1 (2016)

7. V.G. Smelov, A.V. Sotov, A.V. Agapovichev, Key Engin. Mat. 684, 316 (2016)

8. D. Holec, D. Legut, L. Isaeva, P. Souvatzis, H. Clemens, S. Mayer Intermetallics, 61, 85 (2015)

9. R. Pflumm, S. Friedle, M. Schütze, Intermetallics 56, 1 (2015)

10. T. Shanmugasundaram, J. Guyon, J.P. Monchoux, A. Hazotte, E. Bouzy Intermetallics, 66, 141 (2015)

11. X. Meng, W. Cai, F. Chen, L. Zhao Scr. Mater., 54, 1599 (2006)

12. A.V. Balaykin, E.A. Nosova, N.V. Galkina, IOP Conf. Series: Mat. Sc. Engin. 142 (2016) 